\title{
Studies on Mechanical Properties of Jute/E-Glass Fiber Reinforced Epoxy Hybrid Composites
}

\author{
M. R. Sanjay, B. Yogesha \\ Department of Mechanical Engineering, Malnad College of Engineering, Hassan, Visvesvaraya Technological \\ University, Belagavi, India \\ Email: sanjaymrgech@gmail.com
}

Received 12 December 2015; accepted 11 January 2016; published 14 January 2016

Copyright (C 2016 by authors and Scientific Research Publishing Inc.

This work is licensed under the Creative Commons Attribution International License (CC BY). http://creativecommons.org/licenses/by/4.0/

\begin{abstract}
Hybrid materials of any class are essential for current demands. This paper deals with the hybrid effect of composites made of jute/E-Glass fibers which are fabricated by hand layup method using LY556 Epoxy resin and HY951 hardener. The properties of this hybrid composite are determined by testing like tensile, flexural, impact, and inter laminar shear strength which are evaluated experimentally according to ASTM standards. The result of the test shows that hybrid composite of jute/ E-glass fiber has far better properties than that of jute fiber composite. However, it is found that the hybrid composite has better strength as compared to jute fiber composite fabricated separately with glass fiber.
\end{abstract}

\section{Keywords}

Jute Fiber, Glass Fiber, Epoxy, Mechanical Properties

\section{Introduction}

Natural fiber reinforced composite materials are considered as one of the new class of engineering materials. Interest in this area is rapidly growing both in terms of their industrial applications and fundamental research as they are renewable, cheap, completely or partially recyclable, and biodegradable. Among all the natural fiber reinforcing materials, jute appears to be a promising material because it is relatively inexpensive and commercially available in the required form. Glass Fiber Reinforced Polymers (GFRP) is a fiber reinforced polymer made of a plastic matrix reinforced by fine fibers of glass. Fiber glass is a lightweight, strong, and robust material used in different industries due to their excellent properties. Hybridization of glass fiber with Oil palm 
empty fruit bunch (OPEFB) resulted in composites having a superior mechanical performance. A positive hybrid effect is observed in the elongation property. Thus, glass and OPEFB hybrid fiber reinforcement in Phenolformaldehyde (PF) resin resulted in a cost effective and a lightweight composite having good performance qualities. These composites may find applications as structural materials where higher strength and cost considerations are important [1]. The tensile, flexural and impact properties of pineapple leaf fiber (PALF) and sisal reinforced polyester composites are improved by the incorporation of a small amount of glass fibers in these composites, showing positive hybrid effect [2]. The mechanical properties of the composites are improved due to the addition of glass fiber along with palmyra fiber in the matrix and decrease the moisture absorption of the composites [3]. Glass/sugar palm composites are found to have an increase in tensile, flexural, and impact properties with increasing fiber content and the weight ratio of glass/sugar palm fibers [4]. The tensile properties of the flax/glass fiber reinforced hybrid composites were improved with the increasing of glass fiber content. The interlaminar shear strength and the interlaminar fracture toughness of flax/glass fiber reinforced hybrid composites were higher than those of GFRP [5]. Experimental study on untreated woven jute fabric-strengthened polyester composites shows the capability of this renewable wellspring of normal fiber for utilization in various consumable products [6]. The market scenario for composite applications is changing due to the introduction of newer biodegradable polymers. Composite materials reinforced with natural fibers, such as flax, hemp, kenaf and jute, are gaining increasing importance in automotive, aerospace, packaging and other industrial applications [7]. The purpose of this study is to make use of natural fiber like jute fiber, which is abundantly available in India and to incorporate with synthetic fiber like glass fiber to enhance the mechanical properties. In this paper, an effect of hybridization of jute/E-glass fiber reinforced epoxy composites is evaluated. The results of the tests help in determining the potential applications of the jute/E-glass fiber reinforced epoxy composites.

\section{Experimental Procedures}

\subsection{Materials}

Bidirectional Jute fiber mats of thickness $0.4 \mathrm{~mm}$ are purchased from Chandra Prakash \& Co. Jaipur, India. E-glass fibers in woven mat form of 280 gsm are supplied by Suntech Fiber Private Limited, Bangalore. Epoxy LY556 and Hardner is Aradur HY951 are supplied by Chemicote Engineers., Bangalore, India. Table 1 and Table 2 indicate Physical properties of Jute fiber and E-glass fiber respectively.

Table 1. Physical properties of Jute fiber [8].

\begin{tabular}{cc}
\hline Physical property & Jute fiber \\
\hline Density $\left(\mathrm{g} / \mathrm{cm}^{3}\right)$ & 1.4 \\
Elongation at break (\%) & 1.8 \\
Cellulose content (\%) & $50-57$ \\
Lignin content (\%) & $8-10$ \\
Tensile strength (MPa) & $700-800$ \\
Young's modulus (GPa) & 30 \\
\hline
\end{tabular}

Table 2. Physical properties of E-glass fiber.

\begin{tabular}{cc} 
Physical property & Glass fiber \\
\hline GSM & $280 \mathrm{gsm}$ \\
Orientation & plain-woven fabric \\
UTS & $40 \mathrm{GPa}$ \\
Modulus & $1.0 \mathrm{GPa}$ \\
Density & $1.9 \mathrm{~g} / \mathrm{cc}$ \\
\hline
\end{tabular}




\subsection{Specimen Fabrication}

An attempt has been made to fabricate composites by using jute, E-glass and a hybrid of jute/E-glass fiber reinforced epoxy. The mechanical properties like tensile, impact, flexural and inter laminar shear strength are analyzed.

\subsubsection{Preparation of Epoxy-Hardner Mixture}

For each laminate nearly $400 \mathrm{~g}$ of epoxy-hardner mixture is taken. Hardner is taken in the ratio of 1:10 (i.e.; for every $10 \mathrm{~g}$ of epoxy $1 \mathrm{~g}$ of hardner is added). Then the mixture is thoroughly mixed for some time and is used for preparing laminates.

\subsubsection{Fabrication Procedure}

In this study, manual hand layup method is used for preparing composite laminates as shown in Figure 1. First of all, a release gel is sprayed on the mould surface to avoid the sticking of epoxy to the surface. Thin plastic sheets are used at the top and bottom of the mould plate to get a good surface finish of the product. Reinforcement in the form of woven mat jute fabrics and E-Glass fibers are cut as per the mould size and placed at the surface of mould after perspex sheet. Then epoxy in liquid form is mixed thoroughly in suitable proportion with a prescribed hardener (curing agent) and poured onto the surface of mat already placed in the mould. The epoxy is uniformly spread with the help of the brush. The second layer of mat is then placed on the epoxy surface and a roller is moved with a mild pressure on the mat-epoxy layer to remove any air trapped as well as the excess epoxy present. The process is repeated for each layer of epoxy and mat, till the required layers are stacked. After placing the plastic sheet, release gel is sprayed on the inner surface of the top mould plate which is then kept on the stacked layers and the pressure is applied. After curing either at room temperature or at some specific temperature at $60^{\circ} \mathrm{C}-80^{\circ} \mathrm{C}$, the mould is opened and the developed composite part is taken out and further processed. For epoxy based system, normal curing time at room temperature is 24 - 48 hours.

\section{Testing of Composites}

The mechanical properties are carried out by different instruments for the fabricated composites. Table 3 shows laminates designations and layer sequence of each laminate are as shown in Figures 2-5. The thickness of

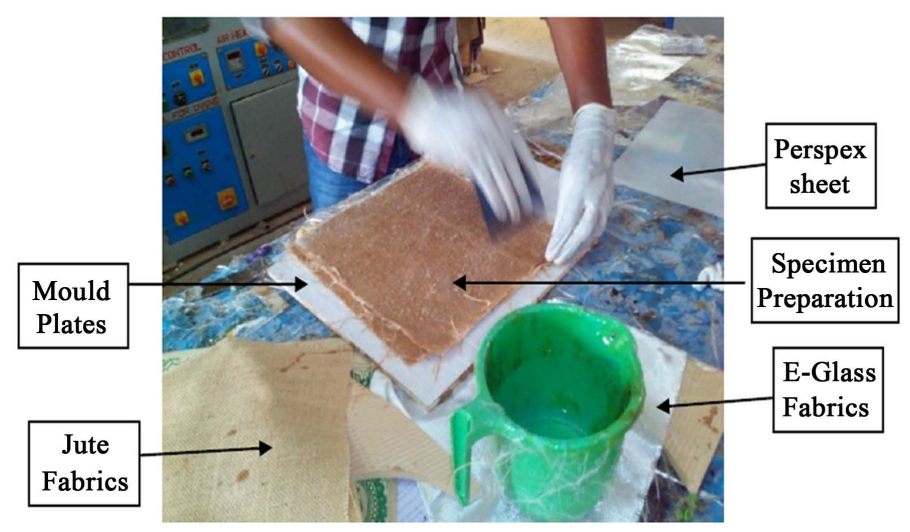

Figure 1. Laminates making using hand lay-up technique.

Table 3. Laminates designations.

\begin{tabular}{cc}
\hline Composites & Compositions \\
\hline L1 & $\mathrm{G}+\mathrm{G}+\mathrm{G}+\mathrm{G}+\mathrm{G}+\mathrm{G}+\mathrm{G}+\mathrm{G}+\mathrm{G}+\mathrm{G}$ \\
$\mathrm{L} 2$ & $\mathrm{~J}+\mathrm{J}+\mathrm{G}+\mathrm{G}+\mathrm{G}+\mathrm{J}+\mathrm{J}$ \\
$\mathrm{L} 3$ & $\mathrm{~J}+\mathrm{J}+\mathrm{J}+\mathrm{J}+\mathrm{J}+\mathrm{J}$ \\
$\mathrm{L} 4$ & $\mathrm{G}+\mathrm{G}+\mathrm{J}+\mathrm{J}+\mathrm{J}+\mathrm{J}+\mathrm{G}+\mathrm{G}$ \\
\hline
\end{tabular}

*(G—Glass layer, J—Jute layer). 


\begin{tabular}{|l|}
\hline Glass Layer \\
\hline Glass Layer \\
\hline Glass Layer \\
\hline Glass Layer \\
\hline Glass Layer \\
\hline Glass Layer \\
\hline Glass Layer \\
\hline Glass Layer \\
\hline Glass Layer \\
\hline Glass Layer \\
\hline
\end{tabular}

Figure 2. Schematic representation of composite 1.

\begin{tabular}{|c|}
\hline Jute Layer \\
\hline Jute Layer \\
\hline Glass Layer \\
\hline Glass Layer \\
\hline Glass Layer \\
\hline Jute Layer \\
\hline Jute Layer \\
\hline
\end{tabular}

Figure 3. Schematic representation of composite 2.

\begin{tabular}{|l|}
\hline Jute Layer \\
\hline Jute Layer \\
\hline Jute Layer \\
\hline Jute Layer \\
\hline Jute Layer \\
\hline Jute Layer \\
\hline
\end{tabular}

Figure 4. Schematic representation of composite 3.

\begin{tabular}{|c|}
\hline Glass Layer \\
\hline Glass Layer \\
\hline Jute Layer \\
\hline Jute Layer \\
\hline Jute Layer \\
\hline Jute Layer \\
\hline Glass Layer \\
\hline Glass Layer \\
\hline
\end{tabular}

Figure 5. Schematic representation of composite 4.

each layer of Jute is $0.4 \mathrm{~mm}$ and each layer of glass is $0.28 \mathrm{~mm}$. As per ASTM standard, the thickness of each laminates is $3 \mathrm{~mm}$, So as to maintain the ASTM standard, considering 10 layers of glass for L1 (Pure glass and epoxy-hardner mixture), for L2 it takes 4 layers of glass and 3 layers of jute (mixture of jute/glass and epoxy-hardner mixture, Note: outer layers are jute), for L3 it takes 6 layers of glass (Pure jute combination and epoxy-hardner mixture) and for L4 it takes 4 layers of glass and 4 layers of jute (mixture of glass/jute and epoxy-hardner mixture, Note: outer layers are glass). 


\subsection{Tensile Test}

The tensile test is done by cutting the composite specimen as per ASTM: D638 standard (sample dimension is $216 \times 19 \times 3 \mathrm{~mm}^{3}$ ). A universal testing machine (UTM) (Model: KIC-2-1000-C) is used for testing with a maximum load rating of $100 \mathrm{KN}$. Composite specimens with different fiber combinations are tested, which are shown in Figure 6. In each case, three samples are tested and the average is determined and noted. The specimen is held in the grip and load is applied and the corresponding deflections are noted. The load is applied until the specimen breaks and break load, ultimate tensile strengths are noted. Tensile stress and strain are recorded and load vs length graphs are generated.

\subsection{Flexural Test}

The flexural test is done in a three point flexural setup as per ASTM: D790 standard (sample dimension is $80 \times$ $8 \times 3 \mathrm{~mm}^{3}$ ). When a load is applied at the middle of the specimen, it becomes bends and fractures as shown in Figure 7. This test is carried out in the UTM from which the breaking load is recorded and load vs length graphs are generated.

\subsection{Impact Test}

The impact test is done in a charpy impact setup as per ASTM: D256 standard (sample dimension is $65 \times 12.5 \times$ $3 \mathrm{~mm}^{3}$ ). The specimens are shown in Figure 8. The specimen must be loaded in the testing machine and allows the pendulum until it fractures or breaks. Using the impact test, the energy needed to break the material is noted and used to measure the toughness of the material and the yield strength. The effect of strain rate on fracture and ductility of the material is analyzed.

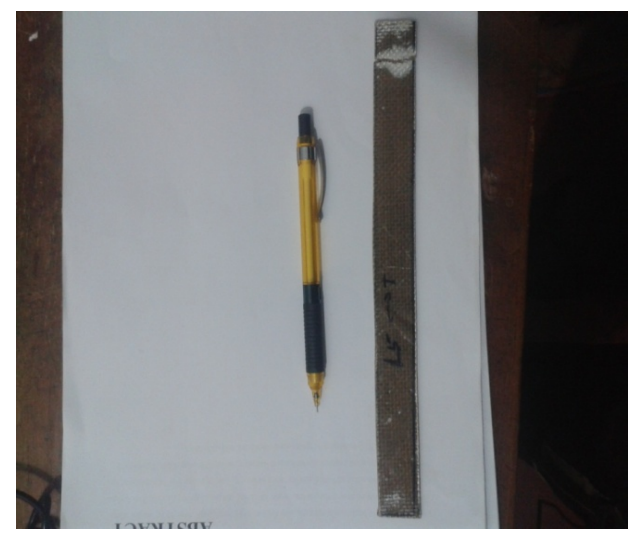

Figure 6. Tensile test specimen.

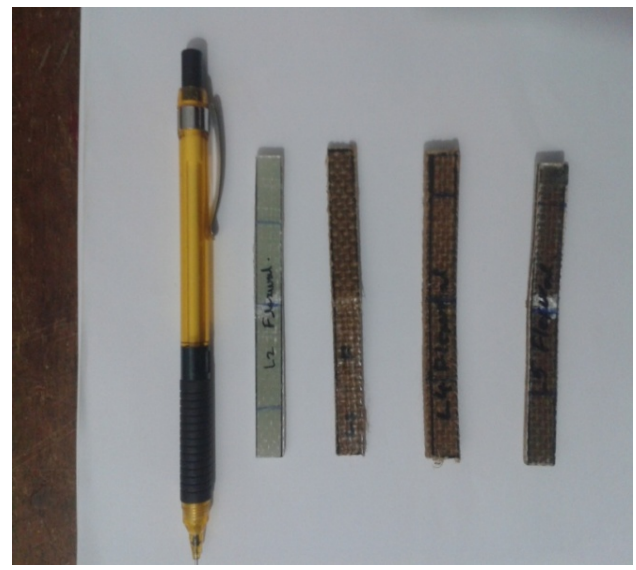

Figure 7. Flexural test specimen. 


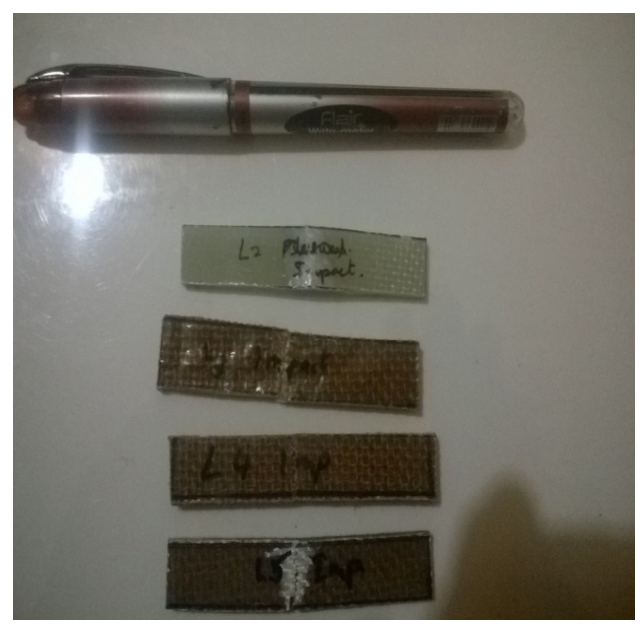

Figure 8. Impact test specimen.

\subsection{Inter Laminar Shear Strength (ILSS) Test}

The ILSS test is done by UTM as per ASTM: D2344 standard (sample dimension is $45 \times 6 \times 3 \mathrm{~mm}^{3}$ ). The specimens are shown in Figure 9. It is one of the quality control parameters for laminated advanced composites. It indicates the maximum shear stress existing between layers of a laminated material.

\section{Results and Discussion}

\subsection{Tensile Properties}

The composites specimens L1, L2, L3, and L4 are tested for tensile properties in UTM and obtained tensile properties are shown in Table 4. The load vs Length curves are shown in Figure 10. The mechanical properties like break load, tensile modulus and ultimate tensile strength (UTS) are shown in Table 4. The stress vs strain curves is shown in Figure 11. Figure 12 shows sample graph of load vs Length obtained by UTM after tensile test. The Laminate L1 which consists of pure glass layers shows a high tensile strength of $280.25 \mathrm{~N} / \mathrm{mm}^{2}$ and L3 which consists of pure jute layers shows a lower tensile strength of $50.641 \mathrm{~N} / \mathrm{mm}^{2}$, but the mixture of jute/glass layers laminates L2 \& L4 shows better results than the L3.

\subsection{Flexural Properties}

The flexural properties including flexural modulus and ultimate flexural strength (UFS) of composites L1, L2, L3 and L4 are tabulated in Table 5. Typical load vs Length curves are shown in Figure 13 and stress vs strain curves are shown in Figure 14. The Laminate L1 shows a high flexural strength of $359.14 \mathrm{~N} / \mathrm{mm}^{2}$ and L3 which shows a lower flexural strength of $165.92 \mathrm{~N} / \mathrm{mm}^{2}$. Again as like tensile strength here also the mixture of jute/glass laminates L2 \& L4 shows better results than the L3.

\subsection{Impact Property}

The loss of energy during impact is the energy absorbed by the specimen during impact. The values are tabulated in Table 6. Figure 15 shows a comparison between energy absorbed by the different combination of composites. The L1 shows very high impact strength compare to all other laminates, but L2 \& L4 shows similar impact strength of $4.35 \mathrm{~J}$ which is better than L3. The L3 shows very poor impact strength of $1.3 \mathrm{~J}$.

\subsection{Inter Laminar Shear Strength (ILSS)}

Table 7 shows ILSS results for different combinations of composites. The load vs length curves are presented in Figure 16 and stress vs strain curves are plotted in Figure 17. The L1 shows better ILSS of $18.304 \mathrm{~N} / \mathrm{mm}^{2}$. There is no rapid change in ILSS of L2, L3 \& L4 which is around $10 \mathrm{~N} / \mathrm{mm}^{2}$, but L4 shows better when to compare to L2 \& L3. 


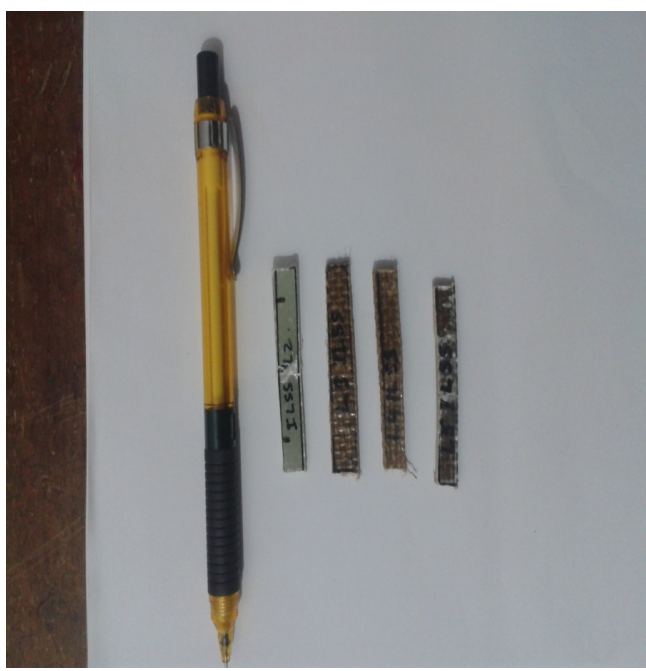

Figure 9. ILSS test specimen.

TENSILE TEST

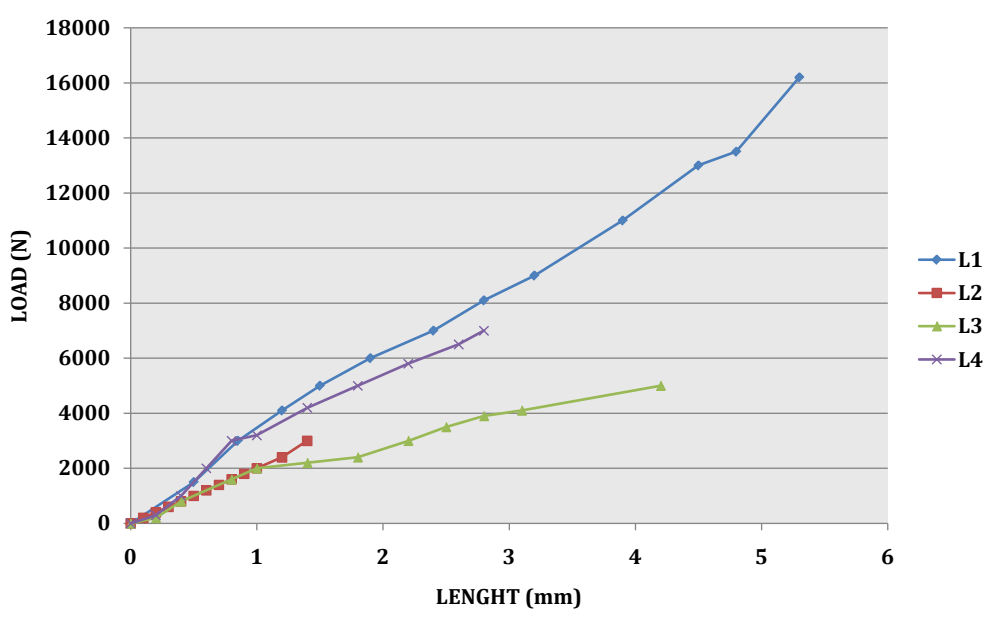

Figure 10. Load vs length graph for tensile test.

TENSILE TEST

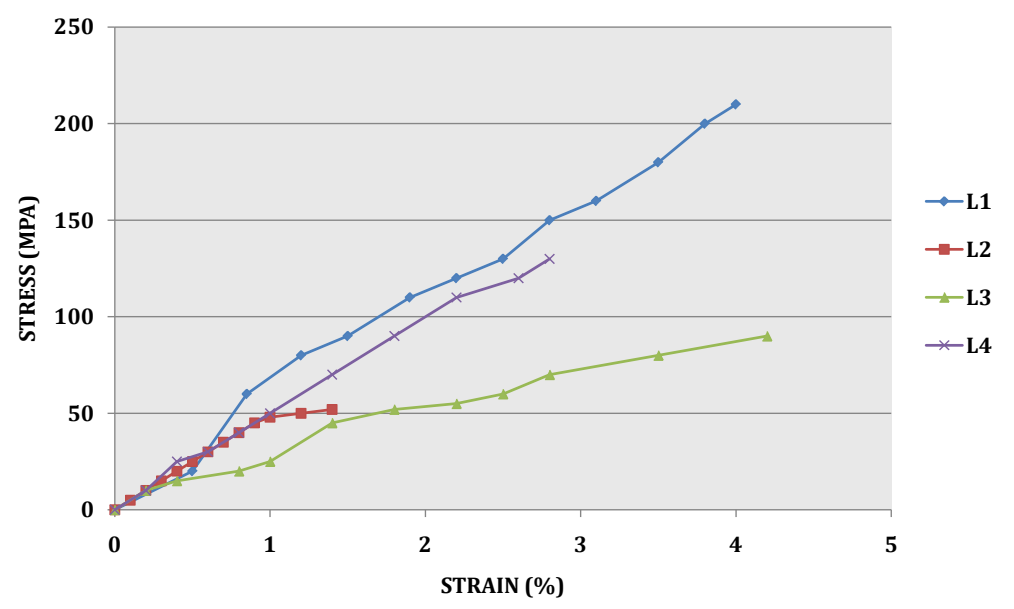

Figure 11. Stress vs strain for tensile test. 


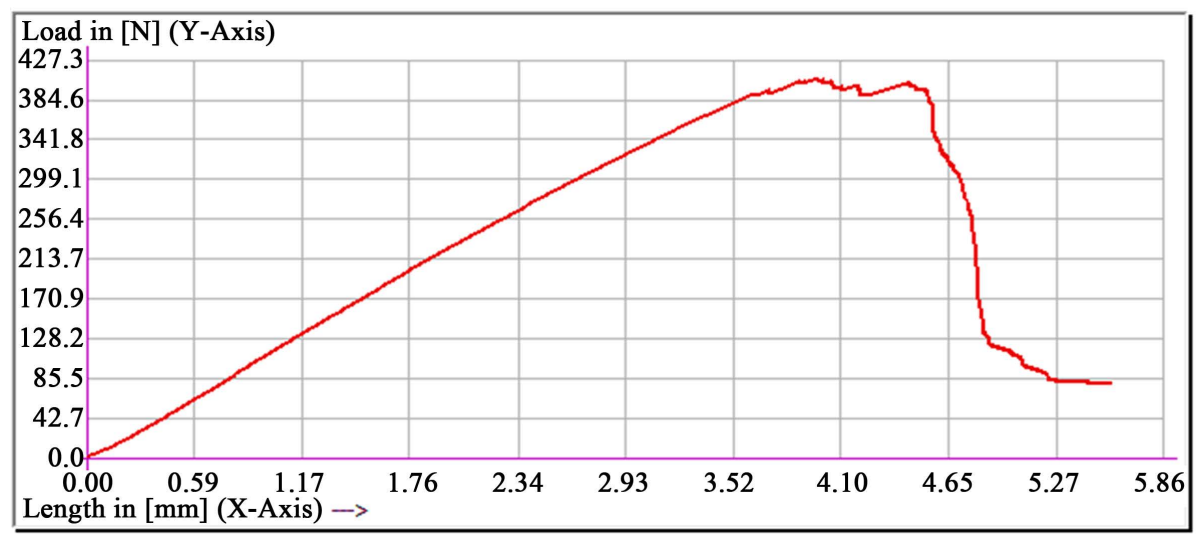

Figure 12. Sample graph obtained from UTM for load vs length (tensile test).

\section{FLEXURAL TEST}

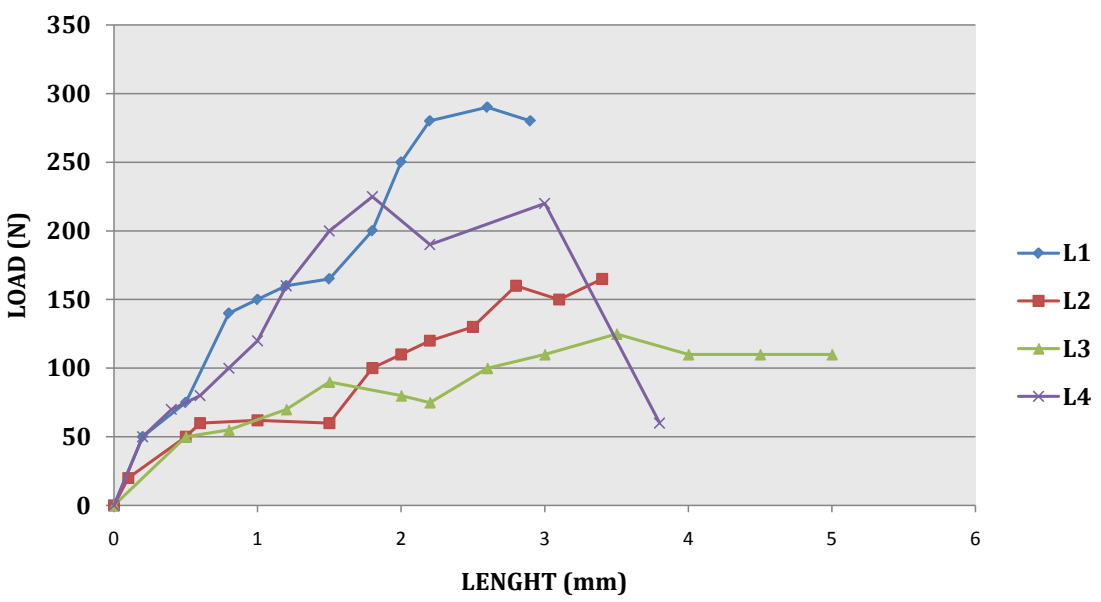

Figure 13. Load vs length graph for the flexural test.

\section{FLEXURAL TEST}

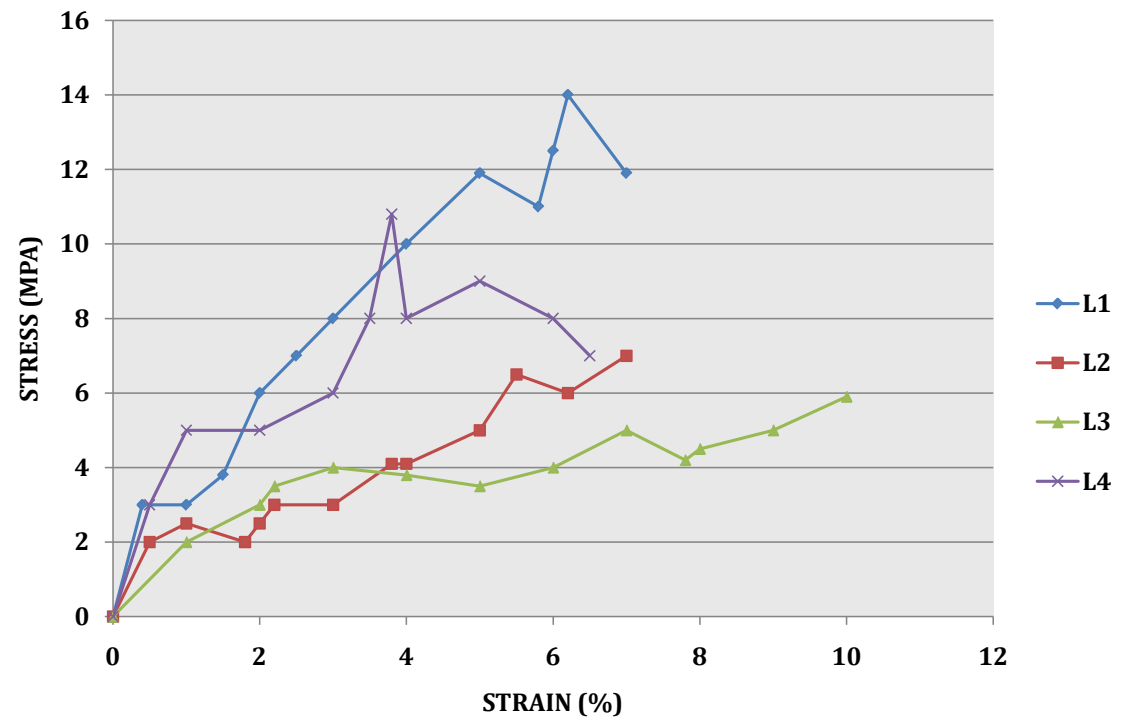

Figure 14. Stress vs strain for flexural test. 


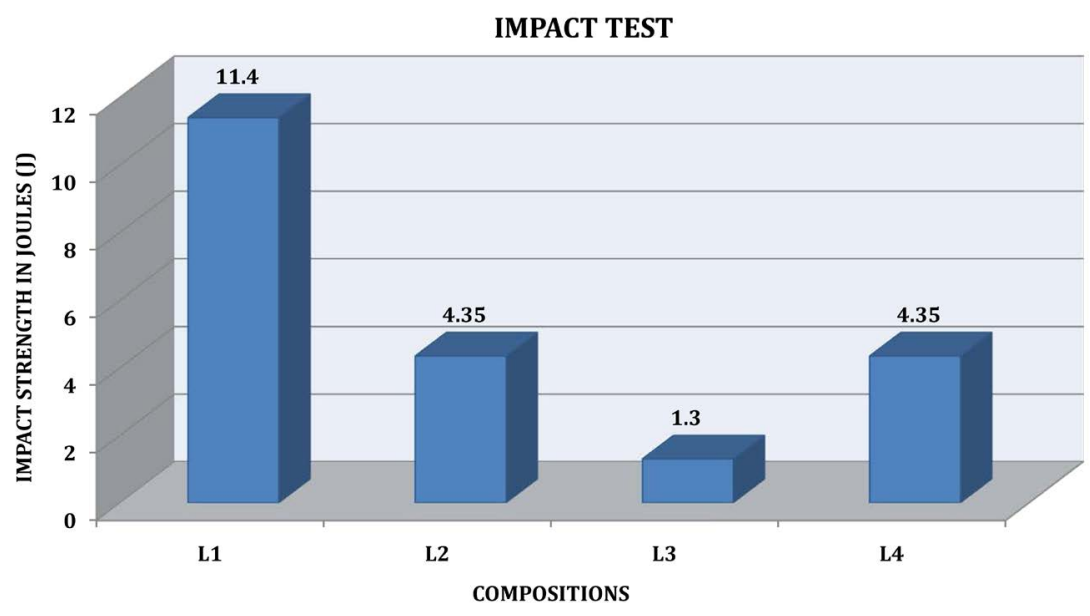

Figure 15. Impact strength of composites.

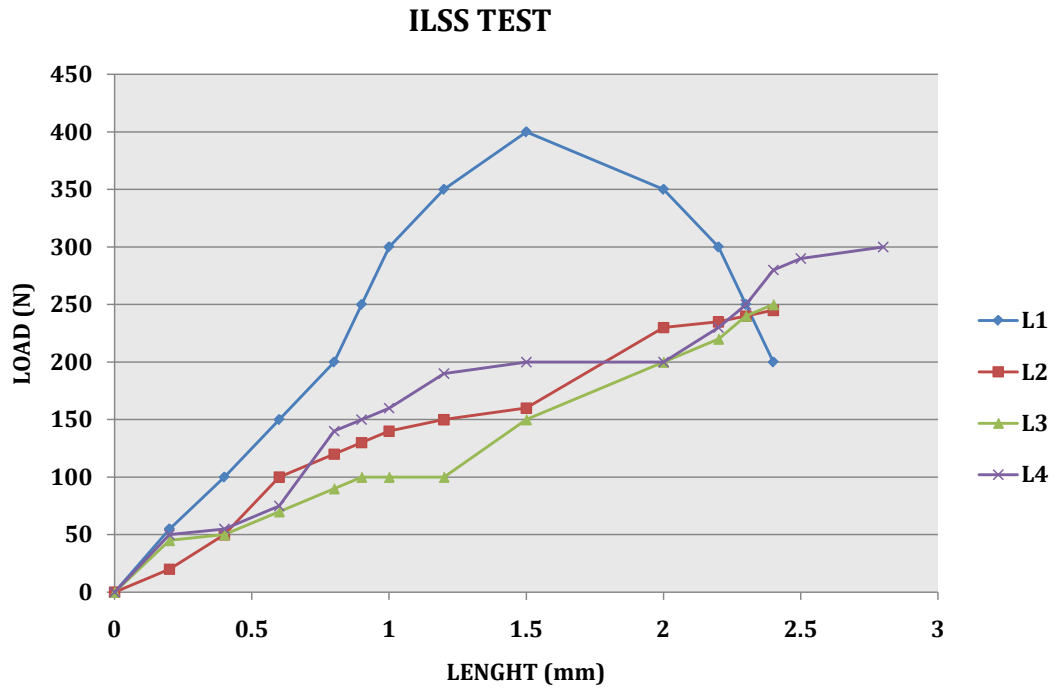

Figure 16. Load vs length graph for ILSS.

\section{ILSS TEST}

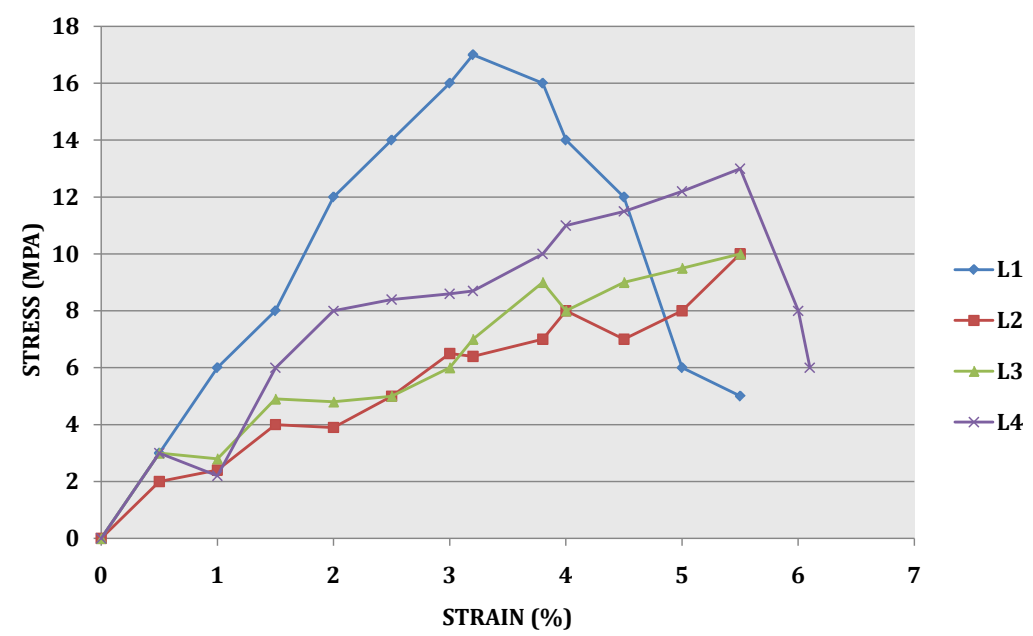

Figure 17. Stress vs strain for ILSS. 
Table 4. Tensile properties of composites.

\begin{tabular}{|c|c|c|c|}
\hline Composites & Break Load (KN) & Tensile Modulus (N/mm²) & UTS $\left(\mathrm{N} / \mathrm{mm}^{2}\right)$ \\
\hline L1 & 9.513 & 5136.27 & 280.25 \\
\hline $\mathrm{L} 2$ & 3.1 & 3822.5 & 94.913 \\
\hline L3 & 14.313 & 2277.23 & 50.641 \\
\hline L4 & 5. 832 & 4589.68 & 123.01 \\
\hline
\end{tabular}

Table 5. Flexural properties of composites.

\begin{tabular}{ccc}
\hline Composites & Flexural Modulus $\left(\mathbf{N} / \mathbf{m m}^{2}\right)$ & UFS $\left(\mathbf{N} / \mathbf{m m}^{2}\right)$ \\
\hline L1 & 254.28 & 359.14 \\
L2 & 137.32 & 212.32 \\
L3 & 105.98 & 165.92 \\
L4 & 295.12 & 258.76 \\
\hline
\end{tabular}

Table 6. Impact strength of composites.

\begin{tabular}{ccc}
\hline Composites & Impact Strength (J) \\
\hline L1 & 11.4 \\
L2 & 4.35 \\
L3 & 1.3 \\
L4 & 4.35 \\
\hline
\end{tabular}

Table 7. Inter laminar shear strength of composites.

\begin{tabular}{ccc}
\hline Composites & ILSS (N/mm $\mathbf{m}^{2}$ \\
\hline L1 & 18.304 \\
L2 & 10.442 \\
L3 & 10.145 \\
L4 & 11.453 \\
\hline
\end{tabular}

\section{Conclusions}

This paper presents the fabrication of hybrid composite using jute and E-glass fiber reinforced epoxy composite by hand layup method. From the tests, the following conclusions are drawn:

- The composite L3 of jute fiber composition shows very poor results when compared with composite L1 of E-Glass fiber composition.

- The hybrid composites L2 \& L4 of Jute/E-Glass fiber compositions show better results than composite L3. Laminate L4 shows better than L2, because it consists of glass as outer layers.

- The incorporation of glass fiber in jute fiber composites enhances the mechanical properties and it leads to the increase of the utilization of natural fibers in various applications.

\section{References}

[1] Sreekala M.S., George, J., Kumaran, M.G. and Thomas, S. (2002) The Mechanical Performance of Hybrid PhenolFormaldehyde-Based Composites Reinforced with Glass and Oil Palm Fibers. Composites Science and Technology, 62, 339-353. http://dx.doi.org/10.1016/S0266-3538(01)00219-6

[2] Mishra, S., Mohanty, A.K., Drzal, L.T., Misra, M., Parija, S., Nayak, S.K. and Tripathy, S.S. (2003) Studies on Mechanical Performance of Biofiber/Glass Reinforced Polyester Hybrid Composites. Composites Science and Technology, 
63, 1377-1385. http://dx.doi.org/10.1016/S0266-3538(03)00084-8

[3] Velmurugan, R. and Manikandan, V. (2007) Mechanical Properties of Palmyra/Glass fiber Hybrid Composites. Composites: Part A, 38, 2216-2226. http://dx.doi.org/10.1016/j.compositesa.2007.06.006

[4] Sapuan, S.M., Lok, H.Y., Ishak, M.R. and Misri, S. (2013) Mechanical Properties of Hybrid Glass/Sugar Palm Fiber Reinforced Unsaturated Polyester Composites. Chinese Journal of Polymer Science, 31, 1394-1403. http://dx.doi.org/10.1007/s10118-013-1342-4

[5] Zhang, Y.L., Li, Y., Ma, H. and Yu, T. (2013) Tensile and Interfacial Properties of Unidirectional Flax/Glass Fiber Reinforced Hybrid Composites. Composites Science and Technology, 88, 172-177. http://dx.doi.org/10.1016/j.compscitech.2013.08.037

[6] Gowda, T.M., Naidu, A.C.B. and Chhaya, R. (1999) Some Mechanical Properties of Untreated Jute Fabric-Reinforced Polyester Composites. Composites: Part A, 30, 277-284. http://dx.doi.org/10.1016/S1359-835X(98)00157-2

[7] Anandjiwala, R.D. and Blouw, S. (2007) Composites from Bast Fibers-Prospects and Potential in the Changing Market Environment. Journal of Natural Fibers, 4.

[8] Sanjay, M.R., Arpitha, G.R. and Yogesha, B. (2015) Study on Mechanical Properties of Natural—Glass Fiber Reinforced Polymer Hybrid Composites: A Review. Materials Today: Proceedings, 2, 2959-2967.

http://dx.doi.org/10.1016/j.matpr.2015.07.264 